\title{
Fabrication and Experimental Analysis of Treated Snake Grass Fiber Reinforced with Polyester Composite
}

\author{
I. Jenish $\left(\mathbb{D},{ }^{1}\right.$ A. Felix Sahayaraj $\mathbb{D},{ }^{2}$ M. Appadurai $\mathbb{C D}^{3}$ E. Fantin Irudaya Raj $\mathbb{D}^{4},{ }^{4}$ P. Suresh, ${ }^{5}$ \\ T. Raja, ${ }^{6}$ Saleh H. Salmen, ${ }^{7}$ Saleh Alfarraj, ${ }^{8}$ and Velu Manikandan' \\ ${ }^{1}$ Department of Applied Mechanics, Seenu Atoll School, Hulhu-medhoo, Addu City, Postal Code-19060, Maldives \\ ${ }^{2}$ Department of Mechanical Engineering, Kalaignar Karunanidhi Institute of Technology, Coimbatore-641402, Tamilnadu, India \\ ${ }^{3}$ Department of Mechanical Engineering, Dr. Sivanthi Aditanar College of Engineering, Tuticorin District-628215, \\ Tamilnadu, India \\ ${ }^{4}$ Department of Electrical and Electronics Engineering, Dr. Sivanthi Aditanar College of Engineering, Tuticorin District-628215, \\ Tamilnadu, India \\ ${ }^{5}$ Department of Mechanical Engineering, VV College of Engineering, Tisaiyanvilai, Tirunelveli-627657, Tamilnadu, India \\ ${ }^{6}$ School of Mechanical Engineering, Vellore Institute of Technology, Chennai-600127, Tamilnadu, India \\ ${ }^{7}$ Department of Botany and Microbiology, College of Science, King Saud University, P.O. Box-2455, Riyadh-11451, Saudi Arabia \\ ${ }^{8}$ Zoology Department, College of Science, King Saud University, Riyadh 11451, Saudi Arabia \\ ${ }^{9}$ College of Environmental \& Bioresource Sciences, Chonbuk National University, Iksan 570752, Republic of Korea
}

Correspondence should be addressed to I. Jenish; jenish@satollschool.edu.mv

Received 4 August 2021; Revised 24 September 2021; Accepted 19 November 2021; Published 22 December 2021

Academic Editor: Alicia E. Ares

Copyright $\odot 2021$ I. Jenish et al. This is an open access article distributed under the Creative Commons Attribution License, which permits unrestricted use, distribution, and reproduction in any medium, provided the original work is properly cited.

\begin{abstract}
The selection of fiber is predominant for natural fiber-reinforced polymer composite materials, which should have easy extraction and good bonding with considerable strength. In this paper, some chemical treatments were done on the fiber material to increase interfacial bonding between the snake grass fiber (Sansevieria ehrenbergii) and polyester matrix, such as alkali treatment (NaOH), potassium permanganate treatment, sodium carbonate treatment, hydrogen peroxide treatment, and calcium carbonate treatment. The chopped snake grass fiber-reinforced polymer composite material was prepared by keeping $25 \mathrm{wt} . \%$ of fiber and $30 \mathrm{~mm}$ fiber length reinforced with an unsaturated polyester resin that was cured with the help of the catalyst methyl ethyl ketone peroxide (MEPK). Cobalt naphthenate was used as an accelerator. Tribological properties were discussed for the highly potential sample with the help of a pin-on-disc wear tester, and the results were analysed by the Taguchi L9 orthogonal array. This paper exhibited the best mechanical and tribological properties among those chemical-treated fibers used in fiber-reinforced composite materials and untreated fibers used in fiber-reinforced composite materials. $\mathrm{CaCO}_{3}$ treatment provided higher tensile strength $(45 \mathrm{MPa})$, impact strength $(3.35 \mathrm{~J})$, and hardness $(27 \mathrm{BHN})$. Finally, the mechanical and tribological characterization of the samples was done with the aid of SEM (scanning electron microscope).
\end{abstract}

\section{Introduction}

Natural fiber-reinforced polymer composite materials have comprehensive interaction over the polymer matrix composite materials due to biodegradability and lower density compared to metals. Fiber surface modification is an identical technique to improve mechanical and tribological properties. In [1], the manual process for preparing the Sansevieria cylindrica/polyester composite is explained, and the properties of the unsaturated polyester are also given. It is concluded that the treated fibers have improved mechanical behavior than untreated fibers and good wettability. Fiber treatment separates the fiber and reduces the lignin content in the fiber while treated with $\mathrm{NaOH} / \mathrm{Na}_{2} \mathrm{SO}_{3}$ [2]. The alkaline treatment $(\mathrm{NaOH})$ increases the bonding of alfa fiber with the matrix, and the brittleness of the fiber also increases when the fiber is dipped 48 hours in the $\mathrm{NaOH}$ solution [3]. Natural fibers have extensive applications in the future. Natural fibers such as flax, hemp, and ramie have a definite mechanical characterization for various applications 
[4]. Sansevieria ehrenbergii fiber, $30 \mathrm{~mm}$ length, treated 30 minutes with $\mathrm{KMnO}_{4}$, and reinforced 30 percent fiber with polyester resin, provided good bonding than the untreated fiber [5]. The coir fiber-reinforced polyester composite is unsuitable for structural applications due to low flexural strength for increasing fiber concentration [6]. Polymer composites' void content and hydrophilic behavior at various temperatures fabricated through resin transfer molding are lower than other processing techniques [7]. The SEM analysis shows that randomly oriented untreated fibers do not give good bonding [8]. Alkali and silane treatments of the hemp fiber-reinforced polylactic acid (PLA) composite improve interfacial adhesion and increase the flexural strength. Generally, compared with short fibers, treated long fibers have higher flexural strength [9]. The surface morphology of treated coconut fiber composite shows excellent matrix-fiber adhesion [10]. Fiber treatment increased the tribological properties of the polymer composites impregnated with natural fibers [11]. Pandanus fiber/polyester composite provided significant improvement on the developed composites for the fiber with an average length of $40 \mathrm{~mm}$. Fiber treatment is necessary to improve the mechanical properties of fiber-reinforced composite materials [12]. Silane treatment increased the tribological properties of the polymer composite by increasing the bonding strength [13].

Natural fibers are the best alternative to synthetic fibers such as glass and Kevlar, fulfilling the current green manufacturing requirement [14]. Natural fibers offer exceptional characteristics such as low density, great tensile strength, and lightness. Natural fibers are derived from various sections of fiber-producing plants. Natural fiber properties are determined by plant type, age, extraction technique, and the environment in which the plant was raised [15]. Various chemical treatments may decrease the incompatibility between plant fibers and polymer matrices. Different surface treatments on biofibers, such as benzoyl peroxide, potassium permanganate, stearic acid, and alkali treatment, improved the chemical, physical, and morphological characteristics of the fibers. Alkali treatment is the first treatment that changes fiber's surface by eliminating amorphous materials and contaminants from the surface [16]. The electrical, thermal, and mechanical properties of Phaseolus vulgaris fiber/unsaturated polyester composites have shown encouraging results for end-use applications [17]. It is critical to adjust the alkali treatment soaking time and concentration in order to achieve the fiber's desirable characteristics [18]. Polyester is defined by the Federal Trade Commission as synthetic fibers that form a long chain containing at least $85 \%$ by weight of an ester of a substituted aromatic carboxylic acid [19]. Since its debut in 1941, polyester has been one of the most widely utilized materials in the industry. Polyester accounted for about 69 percent of total fiber usage in 2017 [20].

The reinforcement and treatment are the following factors in changing the mechanical properties, enclosing this aspect in this study to evaluate mechanical and tribological properties for defined treating time of fiber (Sansevieria ehrenbergii) with the polyester composite.

\section{Experimental Details}

2.1. Materials. The leaves of Sansevieria ehrenbergii were used to extract snake grass fibers (SGFs) gathered from farms around Kanyakumari district, Tamil Nadu, India, by manual process. The chemicals such as sodium hydroxide, sodium carbonate, calcium carbonate, potassium permanganate, and hydrogen peroxide are used for treating the fiber outer surface to increase fiber roughness. The matrix used to prepare the composite material is unsaturated polyester resin with catalyst MEKP. Meanwhile, cobalt naphthenate was also used as an accelerator for the reaction. The matrix (unsaturated polyester), accelerator, and catalyst were supplied from M/S Leo Enterprise, Nagercoil, Tamil Nadu, India.

2.2. Surface Treatments for Fibers. The SGFs extracted from the plant were exposed to various surface treatments such as alkaline $(\mathrm{NaOH})$, potassium permanganate, calcium carbonate, sodium carbonate, and hydrogen peroxide. Before treatment, SGFs were cut into $30 \mathrm{~mm}$ (optimum fiber length).

2.3. Alkali Treatment. The SGFs were dipped with $10 \%$ of $\mathrm{NaOH}$ solution with water for 3 hours. Then, the fibers were rinsed with pure water to remove the lignin content as well as excess chemicals. The fibers were dried for 3 hours in the oven at $70^{\circ} \mathrm{C}[2,3]$.

2.4. Potassium Permanganate Treatment. In this treatment, the SGFs were dipped in a vessel containing $0.5 \%$ potassium permanganate with water for $3 \mathrm{~h}$. Then, the fibers were cleaned with water. Finally, the fibers were dried for 3 hours in the oven at $70^{\circ} \mathrm{C}[2]$.

2.5. Calcium Carbonate Treatment. In this treatment, SGFs were soaked with $10 \% \mathrm{Ca}_{2} \mathrm{CO}_{3}$ solution for $3 \mathrm{~h}$. Then, the treated SGFs were rinsed with pure water. The fibers were dried with the aid of the oven for 3 hours in the oven at $70^{\circ} \mathrm{C}$.

2.6. Sodium Carbonate Treatment. In this treatment, the SGFs were dipped in the solution for $3 \mathrm{~h}$, which contains $10 \%$ of $\mathrm{Na}_{2} \mathrm{CO}_{3}$. Then, treated SGFs were rinsed with fresh water. The fibers were dried using the oven for 3 hours in the oven at $70^{\circ} \mathrm{C}$.

2.7. Hydrogen Peroxide Treatment. The SGFs were dipped in a vessel containing $10 \%$ hydrogen peroxide solution with water for $3 \mathrm{~h}$. The final process was done by cleaning the fiber with water. Then, treated fibers were dried in the oven for 3 hours at $70^{\circ} \mathrm{C}$ to remove the moisture content.

\section{Fabrication of Composite Materials}

The hand lay-up followed by the compression molding method was used to develop the samples [21]. The 
composites were developed separately with untreated as well as chemically treated SGFs. Untreated SGFs were cut into $30 \mathrm{~mm}$ (optimal fiber length) [1].

SGFs (chemically treated) are cut into $30 \mathrm{~mm}$ length as it is a critical fiber length. The fiber content of $25 \%$ by weight was taken for preparing the composite samples [1]. The fibers were filled in the mold cavity and prepressed after closing the mold with mild steel plates to prepare the chopped fiber mat. Polyester resin (97.5\%) was blended with the catalyst ( $2 \%$ of MEKP) and accelerator $(0.5 \%$ of cobalt naphthenate) which are used as binding materials.

Degassed binding material was poured on a chopped fiber mat and spread over the fibers by using a brush. After that, the mold was closed, and $40 \mathrm{kN}$ load was applied on the mild steel plate until complete closure, and this load was kept for $24 \mathrm{~h} \mathrm{[2]}$. The SGF-reinforced composite materials were prepared according to mold size. Similarly, the sample for alkali $(\mathrm{NaOH})$, potassium permanganate-, calcium carbonate-, sodium carbonate-, and hydrogen peroxide-treated SGFs was prepared separately. Figure 1 shows the fabricated composite materials.

\section{Experimental Study}

4.1. Mechanical and Tribological Tests for the Prepared Composite Materials. Tensile test and three-point flexural test were done in Computerized Universal Testing Machine (TUE C-1000) with 100 ton capacity. This tensile testing is carried out under ASTM D638-01 with a crosshead speed of $1 \mathrm{~mm} / \mathrm{min}$ [2]. Impact test was performed with a machine XJJU-5.5, and the ASTM standard is ASTM D256. The Brinell hardness testing machine examined the hardness value of the samples. To analyse the wear behavior of the samples, a two-body dry sliding wear test was conducted in the machine pin-on-disc wear tester. All the experiments are conducted properly, as mentioned in the respective ASTM standard, to avoid errors.

4.2. Scanning Electron Microscope. The reason for failure due to tensile and impact tests would be analysed by imaging analysis using the SEM instrument. SEM analysis was done by the JEOL model 6390 machine. The specimen was cut into $3 \times 3 \times 3 \mathrm{~mm}^{3}$ size in the fracture region to take the SEM image. The magnification range of this machine is $50 \mathrm{x}-500,000 \mathrm{x}$. It is working under the voltage range of 80 to $200 \mathrm{kV}$. The surface of the sample was laminated with a mild layer of gold for better conductivity.

\section{Results and Discussion}

5.1. Mechanical Characterization. The fabricated SGF-reinforced polymer composites undergone various tests to measure the mechanical properties. A variety of mechanical testing was done on the prepared composite materials, and their properties are evaluated. In Figure 2, stress developed against the load is high for $\mathrm{CaCO}_{3}$-treated fiber-reinforced polyester composite material. For the untreated fiber, it is comparatively low because of the presence of lignin content which decreases the bonding strength. The tensile strength of the $\mathrm{CaCO}_{3}$-treated fiber/polyester composite is $45.33 \mathrm{MPa}$. Moreover, from the three-point flexural test result, $\mathrm{CaCO}_{3}$ treatment is comparatively good. It has a reasonable deflection due to bending until fracture, which leads to higher bending strength, as shown in Figure 3. Figure 4 indicates that the $\mathrm{CaCO}_{3}$-treated fiber-reinforced polymer composite material has good resistance against the sudden load compared with other types of treated fiber-reinforced polymer materials. It has an impact strength of 3.35 Joule. The hardness of the developed samples was done with the aid of the Brinell hardness testing machine. The hardness of $27 \mathrm{BHN}$ was obtained in the $\mathrm{CaCO}_{3}$-treated fiber-reinforced polyester composite material which is comparatively higher than other treatments, as shown in Figure 5. The hardness of the material is probably related to the wear resistance of the material.

The $\mathrm{NaOH}$-treated fiber-reinforced polymer composite poorly resists the sudden load due to higher treatment time. The $\mathrm{CaCO}_{3}$-treated fiber-reinforced composite material has good surface hardness compared to other treated snake grass fiber-reinforced polymer composites.

5.2. Tribological Characterization. The coefficient of friction (CoF) of the $\mathrm{CaCO}_{3}$-treated SGF-reinforced polyester was investigated using a pin-on-disc wear tester under the dry sliding wear condition. This treatment produces better properties compared with other treatment methods. The mechanical properties are improved at a significant level by treating with $\mathrm{CaCO}_{3}$. So, $\mathrm{CaCO}_{3}$-treated samples have been subjected to a wear test. To predict the outcome of the results, Taguchi method (L9 orthogonal array) was used. Different levels of input parameters are shown in Table 1, and the design table is given in Table 2.

The optimum level of the input parameter for obtaining minimum wear loss was identified through the signal-tonoise ratio $(\mathrm{S} / \mathrm{N})$ figure as shown in Figures 6 and 7 for wear loss and CoF. Trial run 1 (load $=10 \mathrm{~N}$, sliding velocity $=2 \mathrm{~m} / \mathrm{s}$, and sliding distance $=500 \mathrm{~m}$ ) produces minimum wear loss. The "lower-the-best" condition was implemented to find the minimum wear loss. The optimum CoF was achieved with a load of $10 \mathrm{~N}$, a sliding velocity of $4 \mathrm{~m} / \mathrm{s}$, and a sliding distance of $1500 \mathrm{~m}$. The "higher-the-best" condition was implemented to find optimum $\mathrm{CoF}$ as the wear of the material is analysed for the maximum roughness to evaluate the material's wear behavior. The fabricated material can be used in high gripping applications.

The influence level of each input parameter is calculated from Tables 3 and 4 for wear loss and CoF based on the delta value. For wear loss, the load is ranked as one, sliding distance is ranked as two, and sliding velocity is ranked as three. It described that the load provided more influence on the wear loss. For CoF, the sliding velocity is ranked as one, load is ranked as two, and sliding distance is ranked as three. It described that the sliding velocity provided more influence on the wear loss.

Tables 5 and 6 show the analysis of variance tables for wear loss and CoF. Table 5 contains degrees of freedom (DOFs), adjusted sum of squares (ASS), adjusted mean 


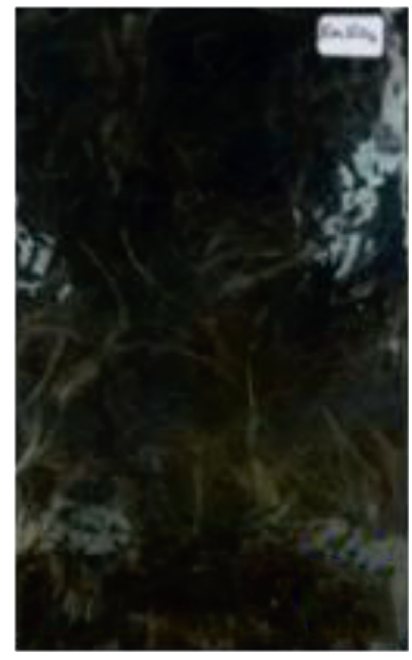

(a)

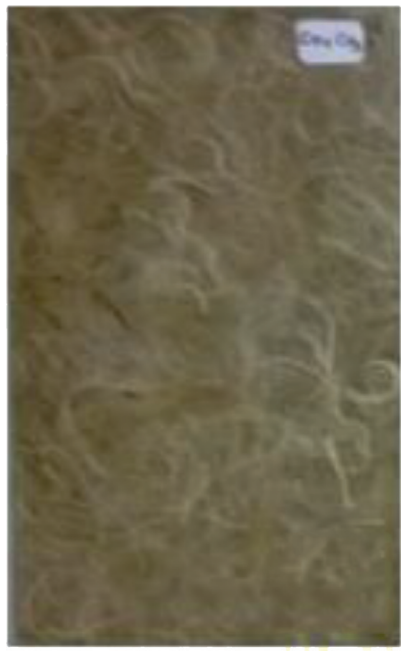

(d)

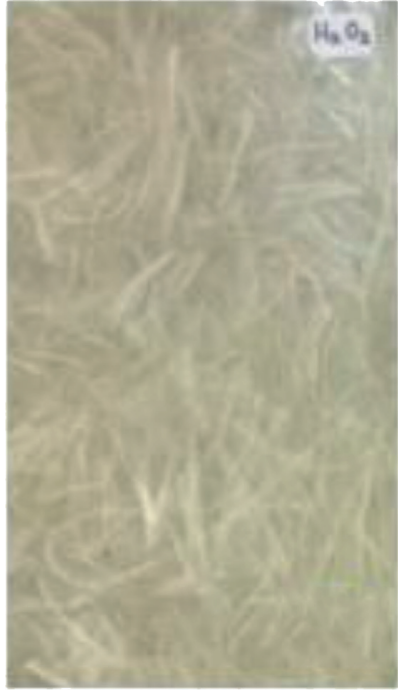

(b)

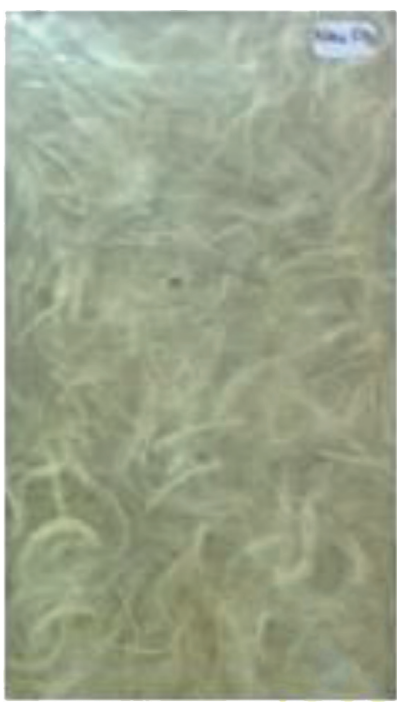

(e)

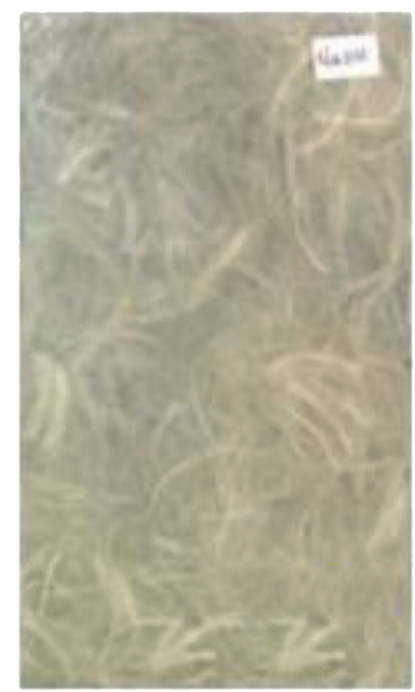

(c)

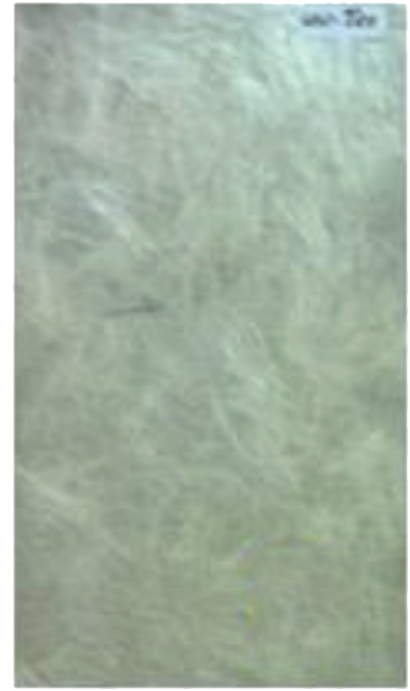

(f)

Figure 1: Fabricated composite materials: (a) potassium permanganate-treated composite, (b) hydrogen peroxide-treated composite, (c) alkali $(\mathrm{NaOH})$ treated composite, (d) calcium carbonate-treated composite, (e) sodium carbonate composite, and (f) untreated composite.

square (AMS), $F$-value, and $P$ value for analysis. The analysis described $95 \%$ confidence level and $5 \%$ significant level of the parameters. In the wear loss table, Adj SS and Adj MS values are below 0.05 , emphasizing that the model is more significant. For wear loss, the $P$ values of load, sliding velocity, and sliding distance are $0.38,0.18$, and 0.496 , respectively. Hence, the impact of sliding distance is more on wear loss. The $P$ value of load, sliding velocity, and sliding distance for CoF is $0.238,0.159$, and 0.185 , respectively. The load has more $P$ value, which emphasizes that the load has more influence on CoF.

The linear regression equation to identify the wear loss and $\mathrm{CoF}$ for any value within the domain was predicted using equations (1) and (2). All coefficient values of the wear loss equation are below 0.05 , which means the model is more significant. The siding distance has a negative coefficient. It indicates that the sliding distance increases with the decrease in wear loss. In the wear loss equation, both load and sliding velocity values are positive, emphasizing that these values increase with an increase in wear loss. The coefficient of load in the CoF equation is negative, which describes that the $\mathrm{CoF}$ decreases while increasing the load. The coefficient values of sliding velocity and sliding distance are positive, showing that the $\mathrm{CoF}$ increases while increasing the sliding velocity and sliding distance.

$$
\begin{aligned}
\text { Wear loss }= & -0.00291+0.000153 \operatorname{load}(\mathrm{N}) \\
& +0.000833 \text { sliding velocity }(\mathrm{m} / \mathrm{s}) \\
& -0.000001 \text { sliding distance }(\mathrm{m}), \\
\text { CoF }= & -0.114-0.0214 \operatorname{load}(\mathrm{N}) \\
& +0.265 \text { sliding velocity }(\mathrm{m} / \mathrm{s}) \\
& +0.000491 \text { sliding distance }(\mathrm{m}) .
\end{aligned}
$$




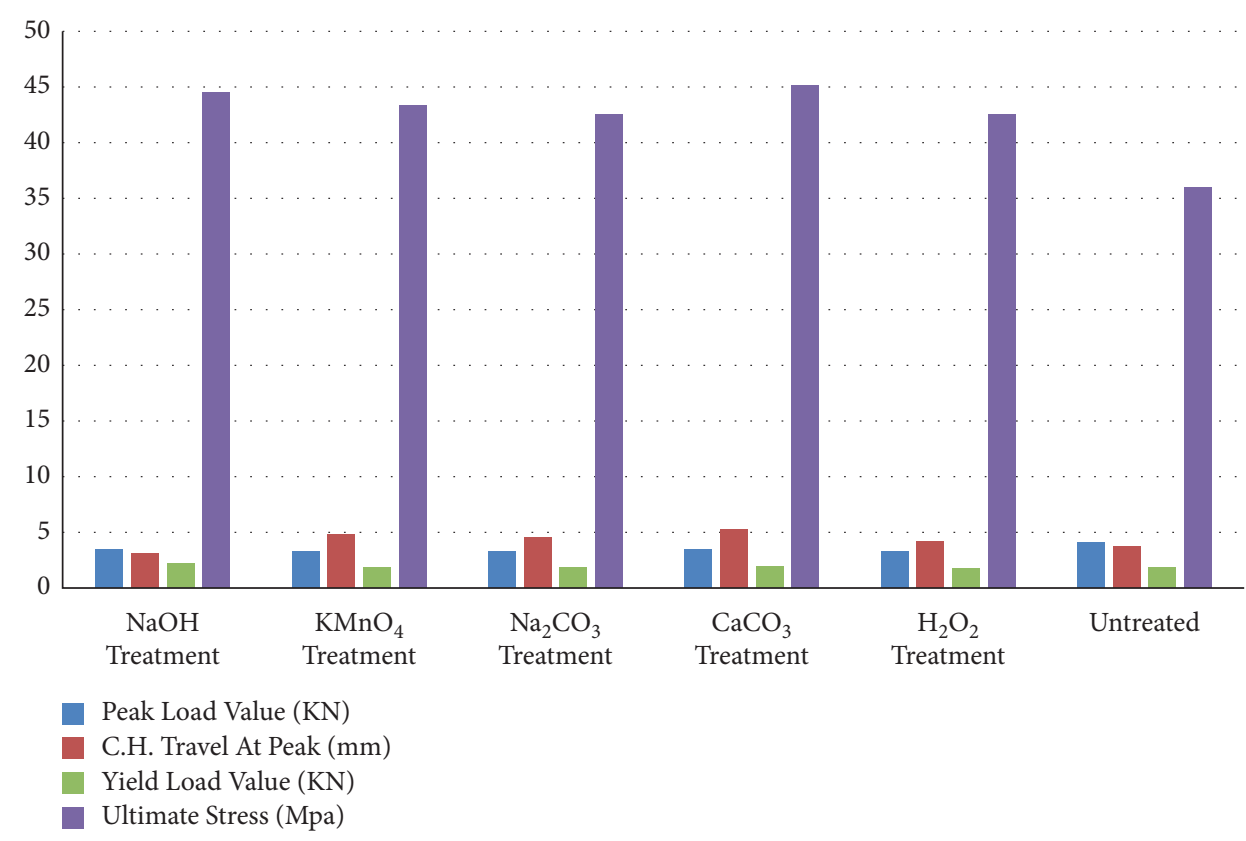

FIGURE 2: Ultimate tensile strength vs. treated and untreated fibers with polyester.

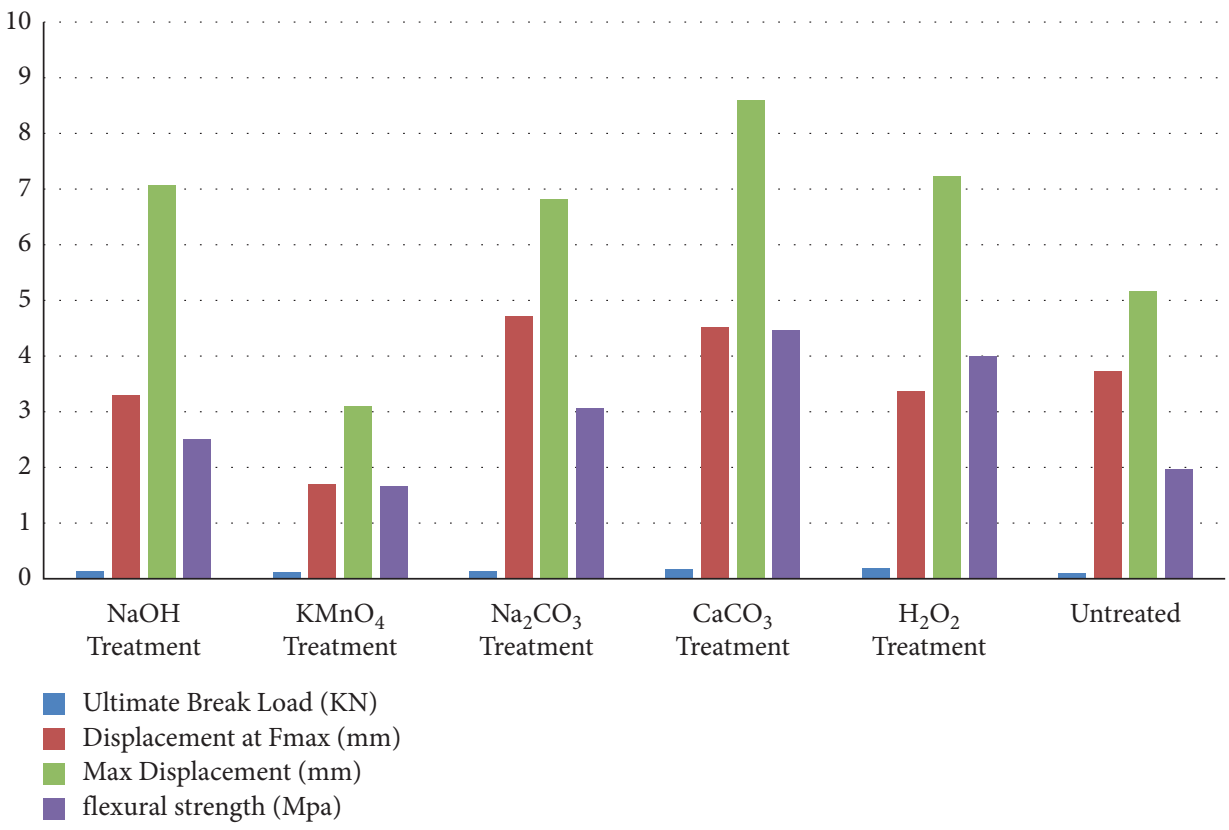

FIGURE 3: Ultimate flexural strength vs. treated and untreated fibers with polyester.

The interaction and independent effect of parameters on wear loss and $\mathrm{CoF}$ are identified in the contour plot of Figures 8 and 9. Different colours with their respective values are listed in the figure. Light colour represents the minimum value, and dark colour represents the maximum value. Figure 8(a) depicts the interaction and independent effect of load as well as sliding velocity on wear loss. The independent effect of load and sliding velocity increases with a slight increase in wear loss. Wear loss increases due to the interaction effect of load and sliding velocity. Trial run 9 (load $=30 \mathrm{~N}$ and sliding velocity $=4 \mathrm{~m} / \mathrm{s}$ ) produces the maximum outcome. The interaction and independent effects of load and sliding distance on wear loss are depicted in Figure 8(b). From the results, it was clear that the wear loss increases steeply while increasing the load. The sliding distance increases with a decrease in wear loss. The loadsliding distance interaction effect significantly increases the wear loss.

The interaction and independent effect of load and sliding velocity on $\mathrm{CoF}$ are depicted in Figure 9(a). Sliding 


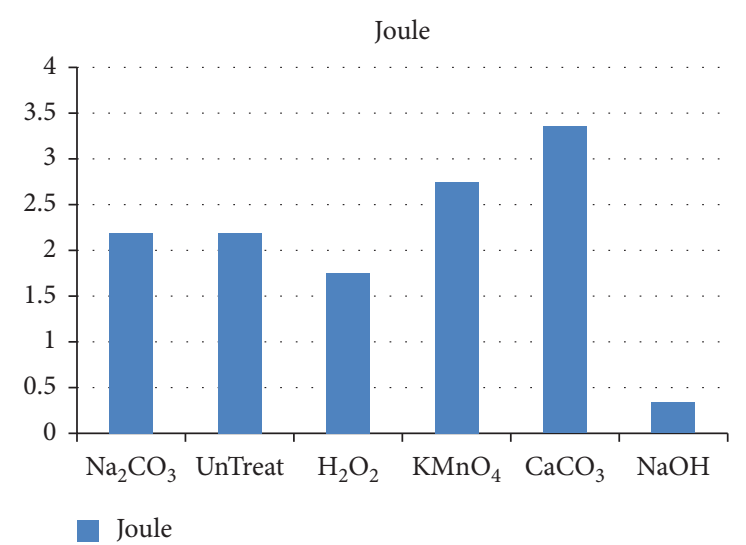

FIGURE 4: Impact strength (Joule) vs. treated and untreated SGFs with polyester.

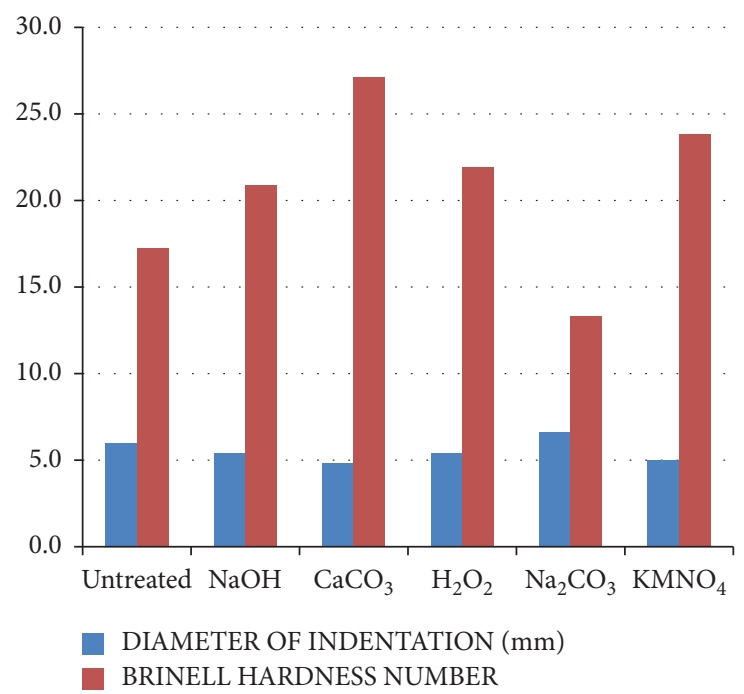

FIGURE 5: BHN vs. treated and untreated SGFs with polyester.

TABLE 1: Level of factors.

\begin{tabular}{|c|c|c|c|c|}
\hline \multirow{2}{*}{ Name } & \multirow{2}{*}{ Units } & \multicolumn{3}{|c|}{ Levels } \\
\hline & & 1 & 2 & 3 \\
\hline Load & $\mathrm{N}$ & 10 & 20 & 30 \\
\hline Sliding velocity & $\mathrm{m} / \mathrm{s}$ & 2 & 3 & 4 \\
\hline Sliding distance & $\mathrm{m}$ & 500 & 1000 & 1500 \\
\hline
\end{tabular}

TABle 2: Design table.

\begin{tabular}{lcccc}
\hline Run & Load $(\mathrm{N})$ & Sliding velocity $(\mathrm{m} / \mathrm{s})$ & Sliding distance $(\mathrm{M})$ & Wear loss \\
\hline 1 & 10 & 2 & 500 & 0.0006 \\
2 & 10 & 3 & 1000 & 0.0007 \\
3 & 10 & 4 & 1500 & 0.0004 \\
4 & 20 & 2 & 1000 & 0.0012 \\
5 & 20 & 3 & 1500 & 0.644 \\
6 & 20 & 4 & 500 & 0.0018 \\
7 & 30 & 2 & 1500 & 0.0013 \\
8 & 30 & 3 & 500 & 0.0021 \\
9 & 30 & 4 & 1000 & 0.0037 \\
\hline
\end{tabular}




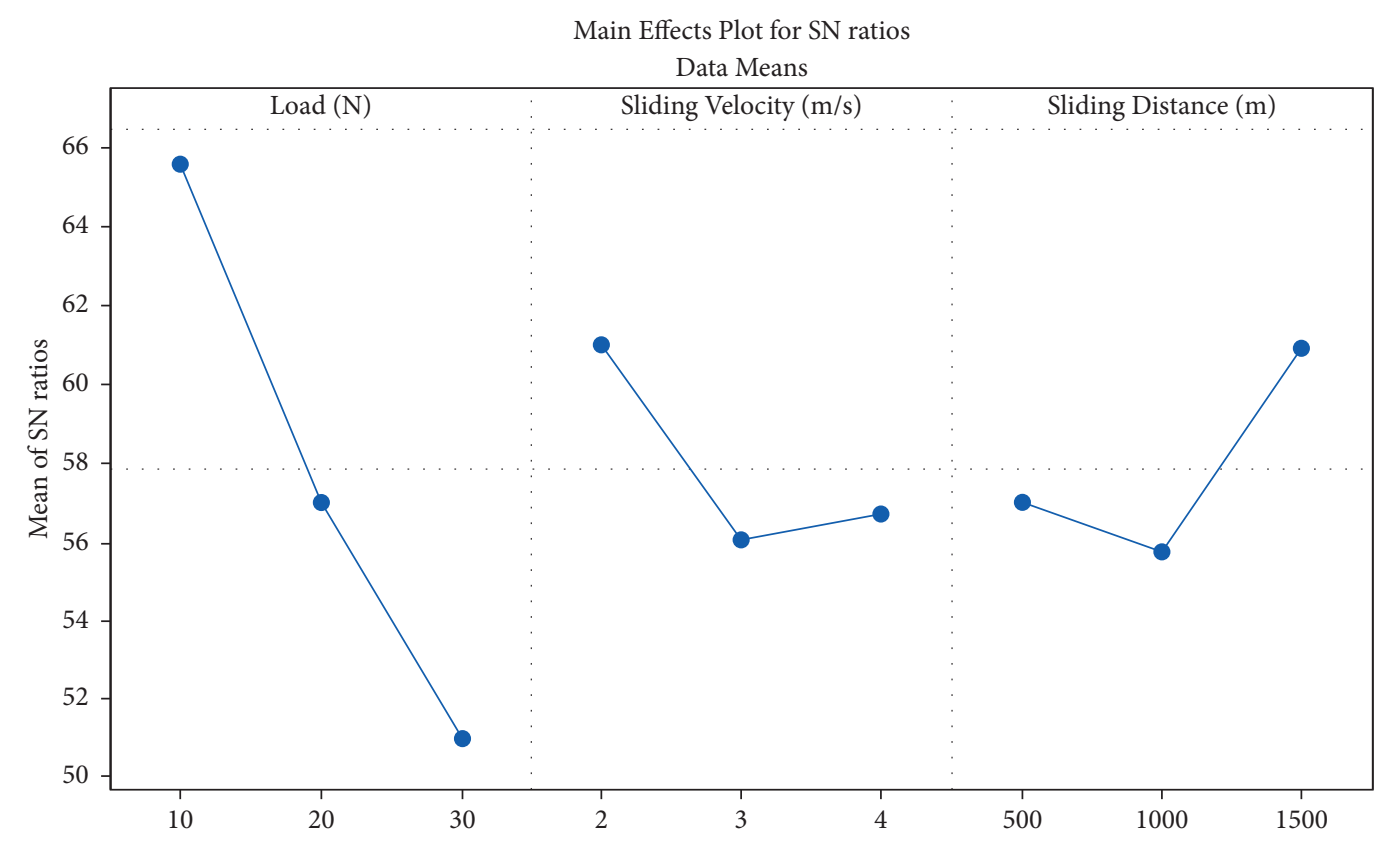

Signal-to-noise: Smaller is better

Figure 6: Main effects' plot for the S-N ratio of wear loss.

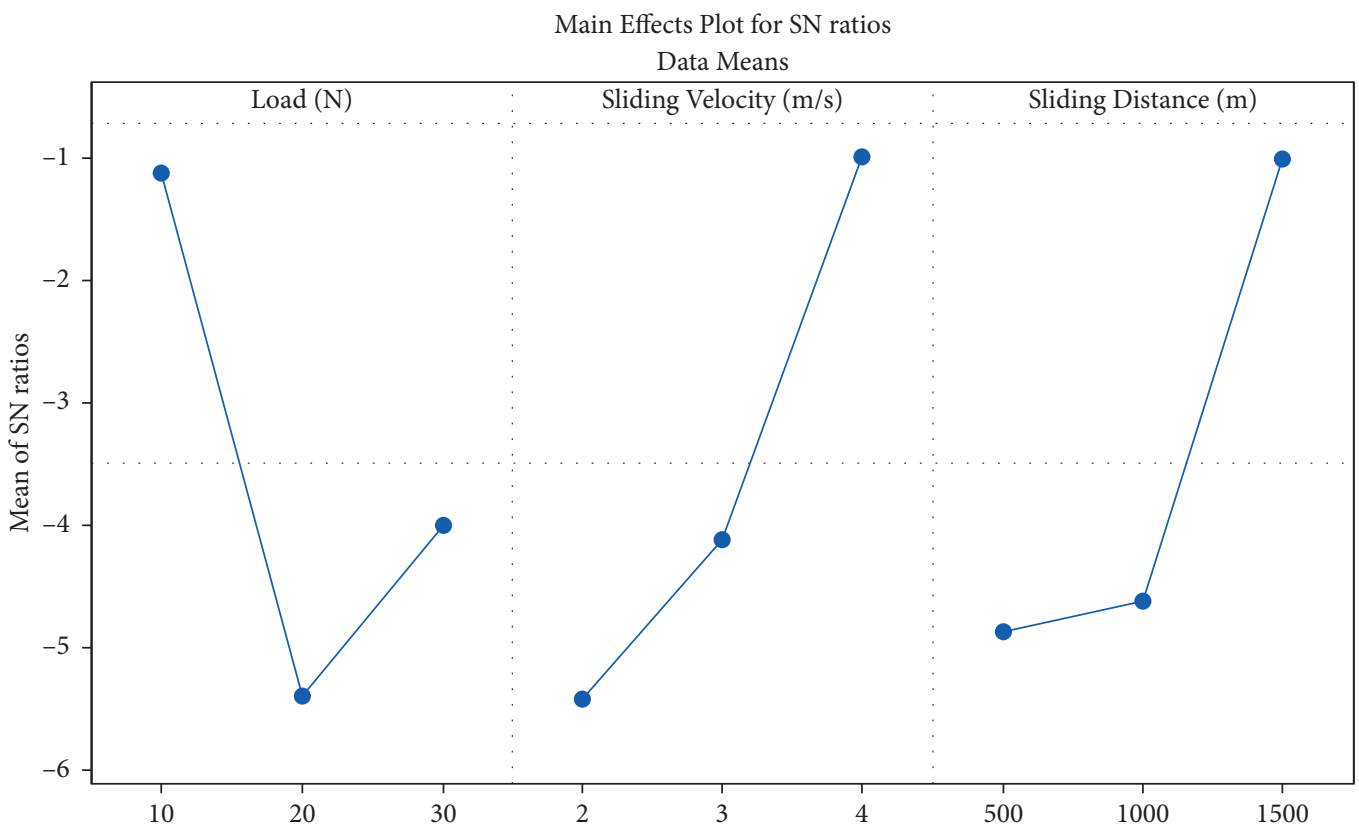

Signal-to-noise: Larger is better

Figure 7: Main effects' plot for the S-N ratio of CoF.

TABLE 3: S/N ratio value of wear loss.

\begin{tabular}{lccc}
\hline Level & Load $(\mathrm{N})$ & Sliding velocity $(\mathrm{m} / \mathrm{s})$ & Sliding distance $(\mathrm{m})$ \\
\hline 1 & 65.61 & 60.95 & 56.93 \\
2 & 57.01 & 55.99 & 55.72 \\
3 & 50.98 & 56.66 & 60.95 \\
Delta & 14.63 & 4.96 & 5.24 \\
Rank & 1 & 3 & 2 \\
\hline
\end{tabular}


TAвLE 4: Signal-to-noise ratio value of $\mathrm{CoF}$.

\begin{tabular}{lccc}
\hline Level & Load $(\mathrm{N})$ & Sliding velocity $(\mathrm{m} / \mathrm{s})$ & Sliding distance $(\mathrm{m})$ \\
\hline 1 & -1.1143 & -5.4126 & -4.8704 \\
2 & -5.3865 & -4.1154 & -4.6179 \\
3 & -4.0041 & -0.9770 & -1.0167 \\
Delta & 4.2722 & 4.4356 & 3.8537 \\
Rank & 2 & 1 & 3 \\
\hline
\end{tabular}

TABle 5: ANOVA test for wear loss.

\begin{tabular}{lccccc}
\hline Source & DOF & ASS & AMS & $F$-value & $P$ value \\
\hline Regression & 3 & 0.000019 & 0.000006 & 3.59 & 0.101 \\
$\quad$ Load $(\mathrm{N})$ & 1 & 0.000014 & 0.000014 & 0.038 \\
Sliding velocity (m/s) & 1 & 0.000004 & 0.000004 & 2.33 & 0.187 \\
$\quad$ Sliding distance (m) & 1 & 0.000001 & 0.000001 & 0.54 & \\
Error & 5 & 0.000009 & 0.000002 & \\
Total & 8 & 0.000028 & & \\
\hline
\end{tabular}

Table 6: ANOVA test for CoF.

\begin{tabular}{lccccc}
\hline Source & DOF & ASS & AMS & $F$-value & $P$ value \\
\hline Regression & 3 & 1.0591 & 0.3530 & 0.195 \\
$\quad$ Load $(\mathrm{N})$ & 1 & 0.2756 & 0.2756 & 0.30 & 1.79 \\
Sliding velocity (m/s) & 1 & 0.4213 & 0.4213 & 2.74 & 0.159 \\
$\quad$ Sliding distance (m) & 1 & 0.3621 & 0.3621 & & \\
Error & 5 & 0.7685 & 0.1537 & \\
Total & 8 & 1.8276 & & \\
\hline
\end{tabular}

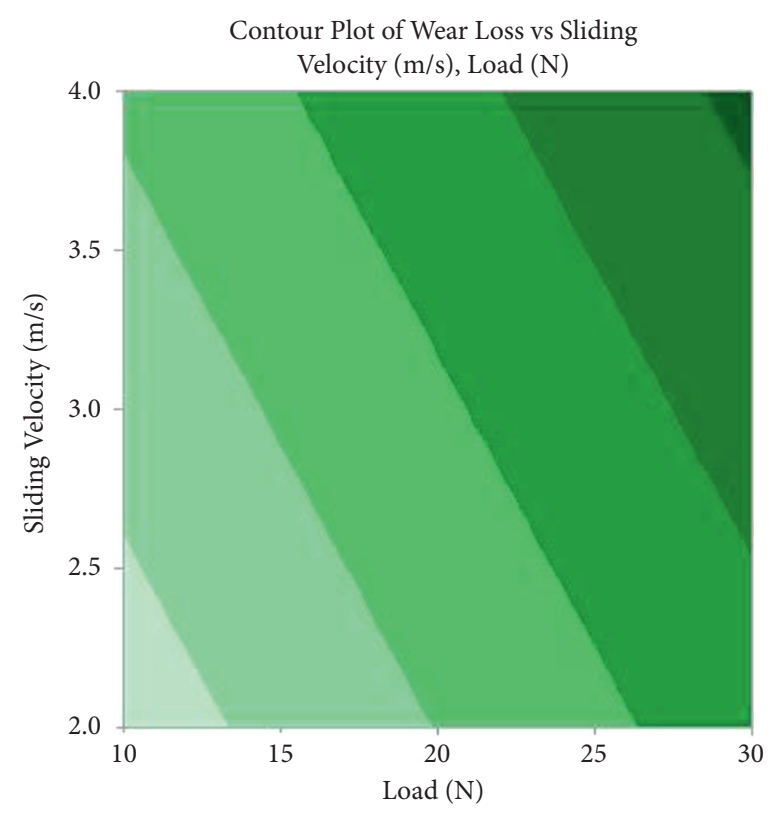

Wear Loss

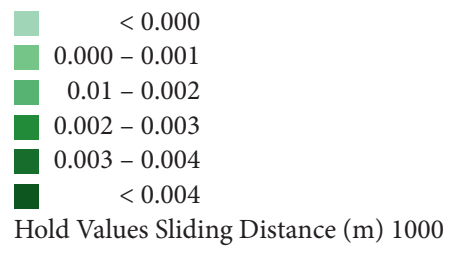

(a)

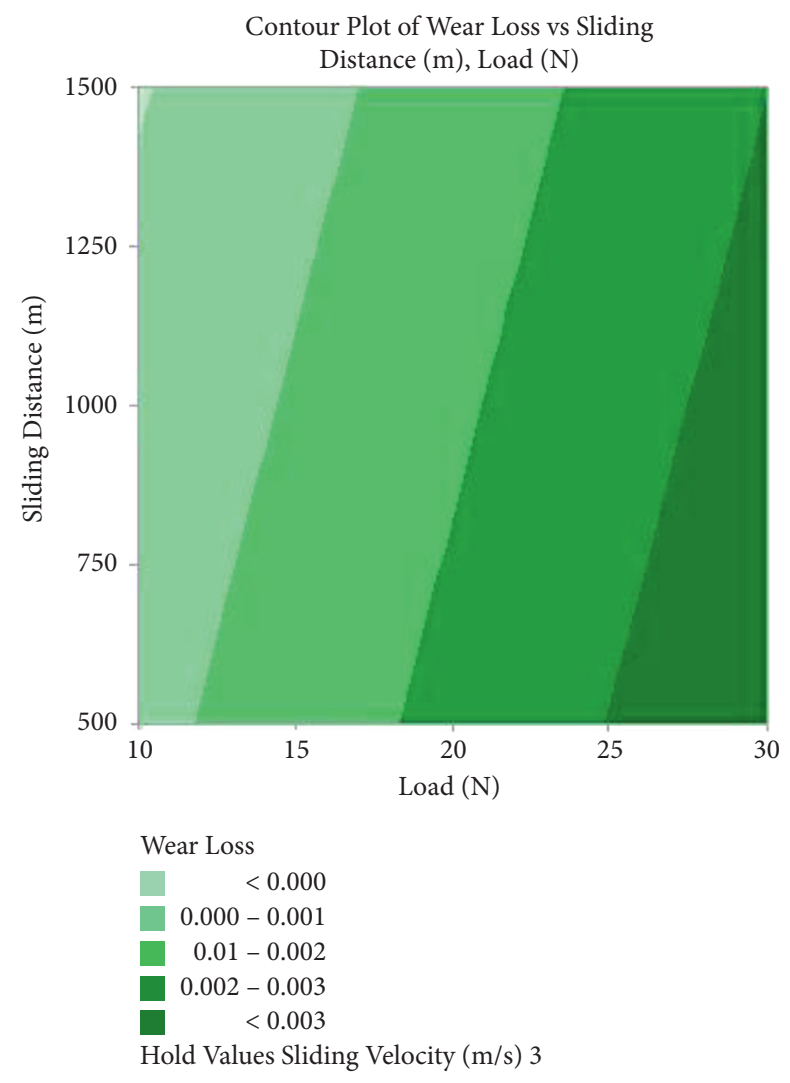

(b)

Figure 8: Wear loss (contour plot). (a) Load vs. sliding velocity. (b) Load vs. sliding distance. 


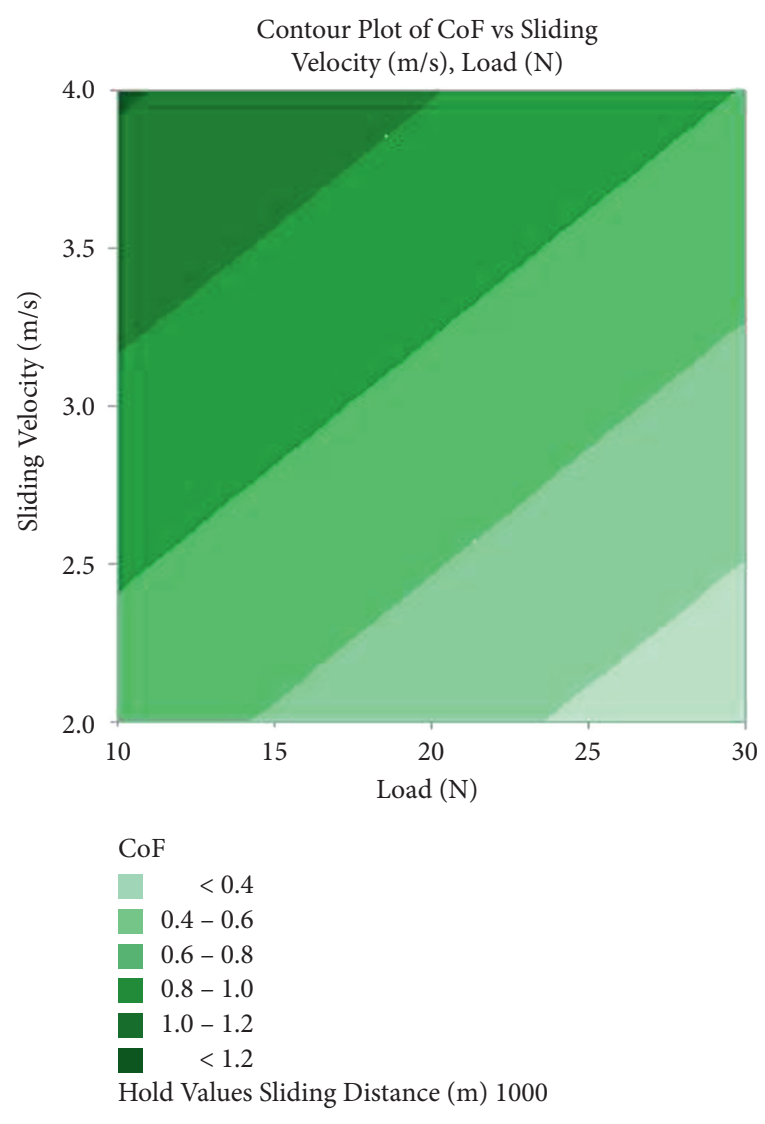

(a)

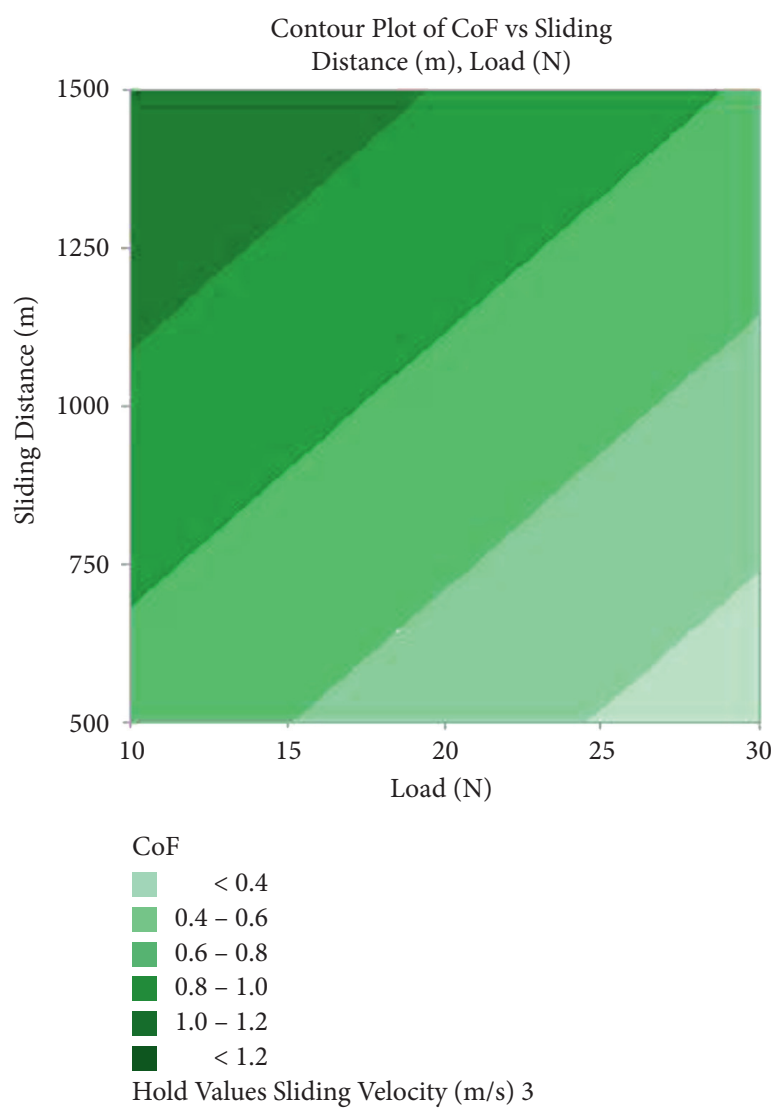

(b)

Figure 9: CoF (contour plot). (a) Load vs. sliding velocity. (b) Load vs. sliding distance.

velocity increases the outcome of CoF. However, the load increases with the decrease in CoF. CoF increases due to the interaction effect of load and sliding velocity. The optimum result was obtained at the load of $10 \mathrm{~N}$ and sliding velocity of $4 \mathrm{~m} / \mathrm{s}$. Figure 9 (b) shows the interaction and independent effect of load and sliding distance on CoF. The sliding distance increases with an increase in CoF. The interaction effect is not significantly affecting the CoF.

\subsection{Scanning Electron Microscope (SEM) Analysis. SEM} images revealed the inadequate bonding of SGFs with polyester. Under tensile and impact loading, matrix-fiber debonding, fiber pullout, matrix fracture, and fiber fracture were seen in both the untreated snake fibers with polyester and the $\mathrm{NaOH}$-treated snake grass fibers with polyester composites. From the tensile and impact fractography results, it was clear that $\mathrm{CaCO}_{3}$-treated snake grass fiber with polyester was good. Under tensile and impact loading, matrix and fiber fracture was the most common failure mechanism in short $\mathrm{CaCO}_{3}$-treated snake grass fiber with polyester composites. Figures 10(a)-10(c) show tensile test images of the untreated fiber with polyester and $\mathrm{CaCO}_{3}$-treated fiber with polyester composite, respectively. Figures $11(\mathrm{a})$ and 11(b) show the impact test images of the $\mathrm{NaOH}$-treated fiber with polyester and $\mathrm{CaCO}_{3}$-treated fiber with polyester composite, respectively.

The SEM images of the $\mathrm{CaCO}_{3}$ composite materials (worn surface) are given in Figure 12. Figure 12(a) shows the SEM images of the worn surface for the minimum input conditions (load $=10 \mathrm{~N}$, sliding velocity $=2 \mathrm{~m} / \mathrm{s}$, and sliding distance $=500 \mathrm{~m}$ ). It shows very minimum wear on the surface due to the strong matrix-fiber bonding. The contour plot emphasizes that both sliding distance and sliding velocity do not cause any effect on the wear loss. Similarly, minimum damages occurred at maximum sliding velocity and sliding distance, as shown in Figure 12(b). The main wear mechanisms are matrix pitting, microgrooves, and debris. More damages occurred at the maximum load condition, as shown in Figure 12(c). High wear loss occurred due to increased load (high pressure), which broke the interlaminar structure's cohesive and adhesive bonds. The main wear mechanisms are matrix cutting, fiber-matrix detachment, matrix pitting, and delamination. 


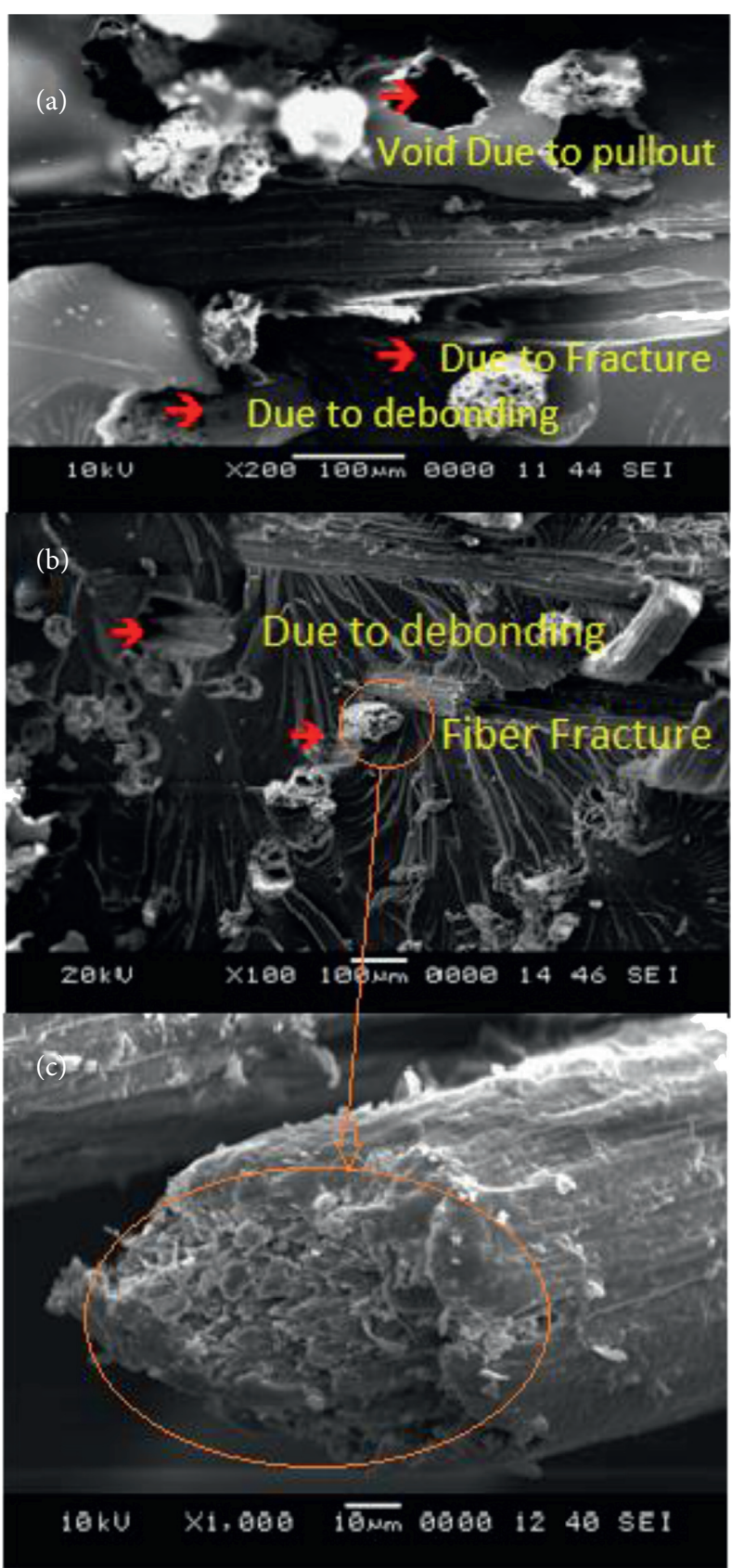

Figure 10: Tensile test: (a) untreated fiber with polyester; (b, c) $\mathrm{CaCO}_{3}$-treated fiber with polyester. 

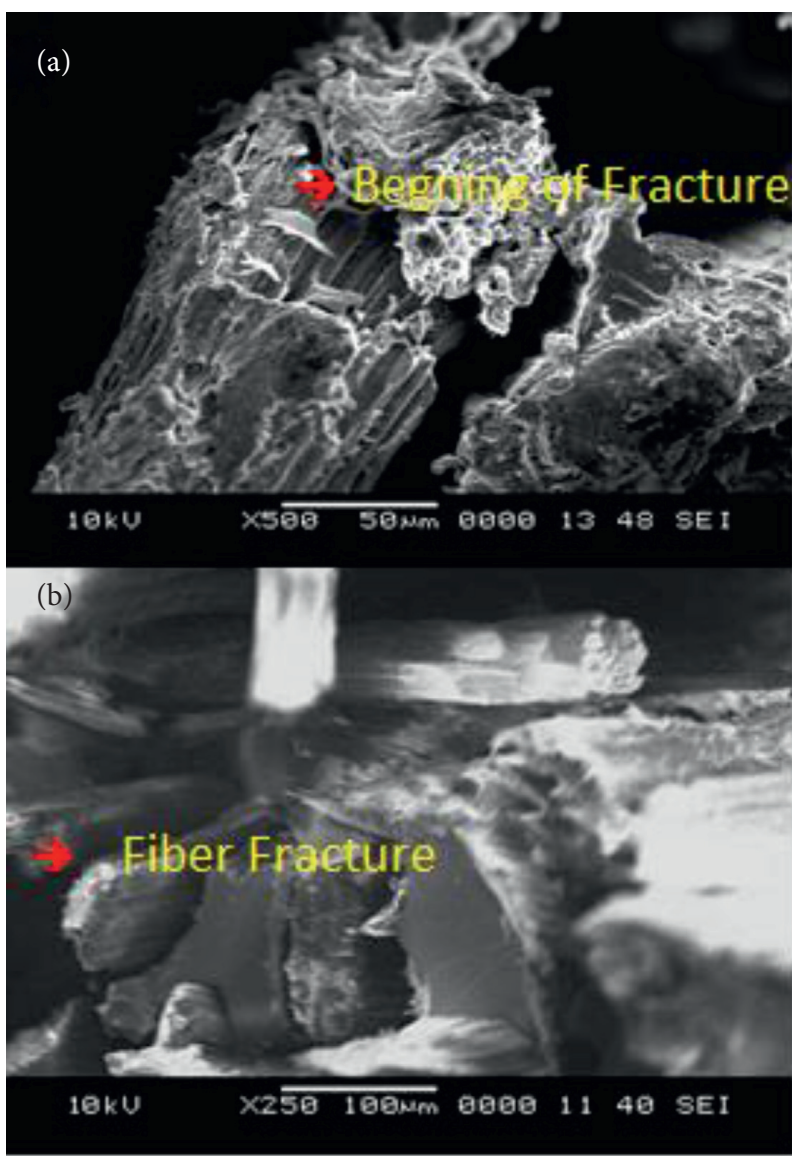

FIgURE 11: Impact test: (a) $\mathrm{NaOH}$-treated fiber with polyester; (b) $\mathrm{CaCO}_{3}$-treated fiber with polyester.

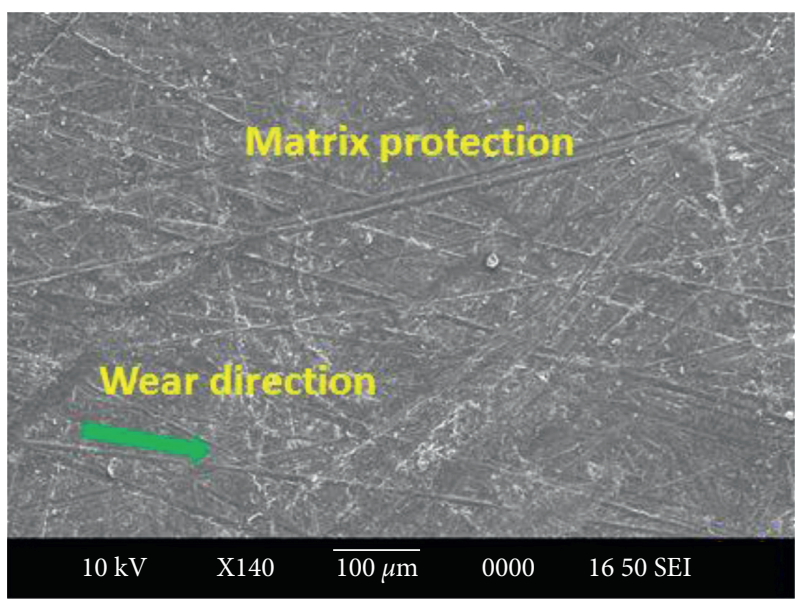

(a)

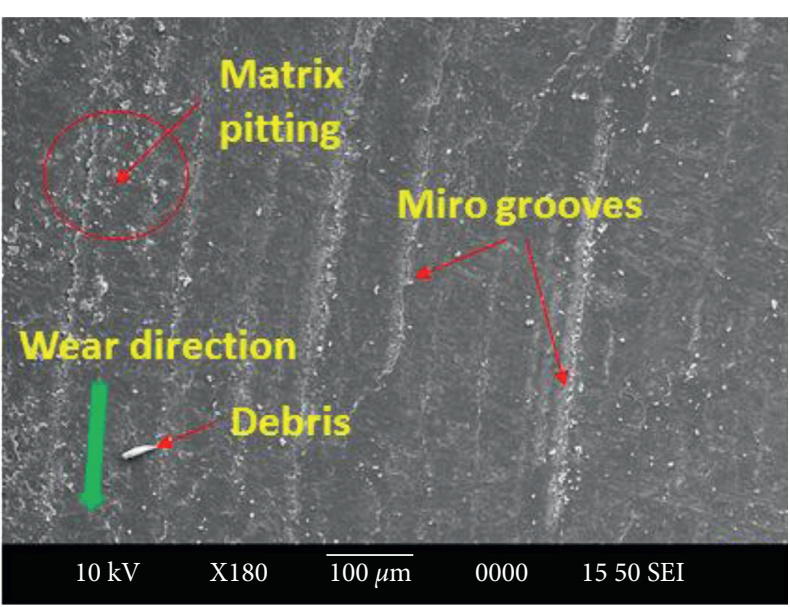

(b)

Figure 12: Continued. 


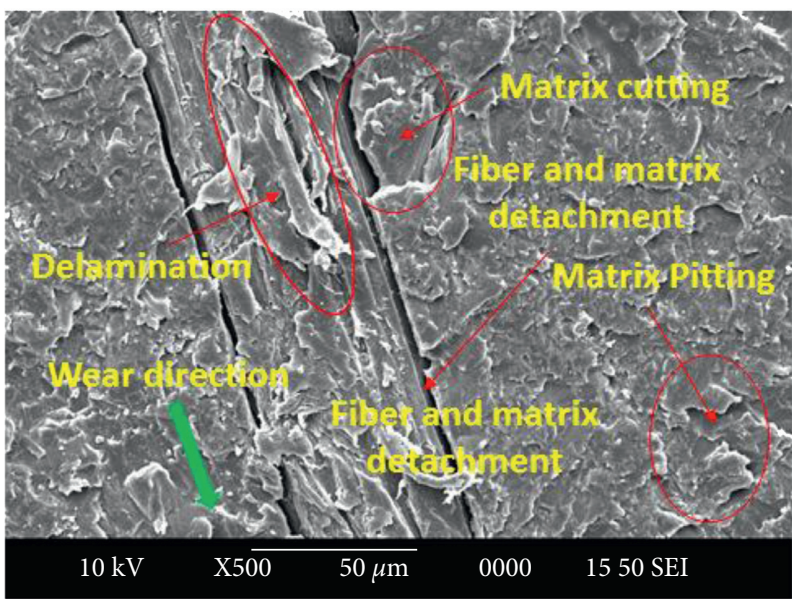

(c)

FIGURE 12: SEM images of worn surfaces using a variety of input parameters such as load, sliding velocity, and sliding distance. (a) $10 \mathrm{~N}, 2 \mathrm{~m} /$ s, and $500 \mathrm{~m}$. (b) $10 \mathrm{~N}, 4 \mathrm{~m} / \mathrm{s}$, and $1500 \mathrm{~m}$. (c) $30 \mathrm{~N}, 4 \mathrm{~m} / \mathrm{s}$, and $1000 \mathrm{~m}$.

\section{Conclusion}

In this work, snake grass fiber (Sansevieria ehrenbergii) was treated with different chemicals such as $\mathrm{NaOH}$, potassium permanganate, calcium carbonate, sodium carbonate, and hydrogen peroxide to eliminate lignin for getting better fiber-reinforced polyester composite materials. The experimental investigation of mechanical and tribological behavior of treated SGF-reinforced polyester composites derives the following conclusions:

(i) This research demonstrates that the successful manufacture of chemical-treated snake grass fiberreinforced polyester composites with 25\% fiber reinforcement was done by the hand lay-up method.

(ii) Calcium carbonate-treated fiber-reinforced polyester composite has the highest hardness value of $27 \mathrm{BHN}$ in the hardness test, which is more than $50 \%$ compared to untreated snake grass fiberreinforced polyester composite materials.

(iii) From the tensile test, the calcium carbonate-treated reinforced composite has high mean ultimate strength of $45.335 \mathrm{~N} / \mathrm{mm}^{2}$.

(iv) Calcium carbonate-treated fiber-reinforced composite

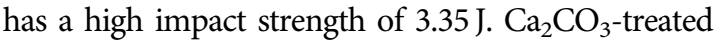
fiber-reinforced composite has a high ultimate flexural strength of $4.5 \mathrm{~N} / \mathrm{mm}^{2}$.

(v) In the overall view, the newly experimented calcium carbonate-treated fiber-reinforced composite has very good mechanical properties.

(vi) The SEM images of the fractured samples showed the reason for the poor adhesion and fiber fraction for untreated fiber-reinforced polymer composite materials. After the treatment, comparatively good adhesion, decrement in fiber pullout, and minimum debonding were identified. The maximum damages occurred at $30 \mathrm{~N}$ load, which is substantiated by SEM images. Sliding velocity and sliding distance increased with an increase in CoF. The identified main wear mechanisms are matrix cutting, matrix pitting, microgrooves, delamination, fiber-matrix detachment, and debris.

(vii) $\mathrm{CaCO}_{3}$ treatment is inevitable to improve the wear resistance. Because of the strong fiber-matrix adhesion, sliding velocity and sliding distance have negligible wear loss. However, applied load increases with an increase in wear loss.

\section{Data Availability}

The data used to support the findings of this study are included within the article.

\section{Conflicts of Interest}

The authors declare that there are no conflicts of interest regarding the publication of this article.

\section{Acknowledgments}

The authors thank Seenu Atoll School, Hulhumeedhoo, Maldives, and Kalaignar Karunanidhi Institute of Technology, Coimbatore, for providing the facility support to complete this research work and this project was supported by Researchers Supporting Project number (RSP-2021/385) King Saud University, Riyadh, Saudi Arabia.

\section{References}

[1] V. S. Sreenivasan, D. Ravindran, V. Manikandan, and R. Narayanasamy, "Influence of fibre treatments on mechanical properties of short Sansevieria cylindrica/polyester composites," Materials \& Design, vol. 37, pp. 111-121, 2012.

[2] G. W. Beckermann and K. L. Pickering, "Engineering and evaluation of hemp fibre reinforced polypropylene composites: fibre treatment and matrix modification," Composites 
Part A: Applied Science and Manufacturing, vol. 39, no. 6, pp. 979-988, 2008, Jun. 2008.

[3] M. Rokbi, H. Osmani, A. Imad, and N. Benseddiq, "Effect of chemical treatment on flexure properties of natural fiberreinforced polyester composite," Procedia Engineering, vol. 10, pp. 2092-2097, 2011, Jan. 2011.

[4] D. B. Dittenber and H. V. S. Gangarao, "Critical review of recent publications on use of natural composites in infrastructure," Composites Part A: Applied Science and Manufacturing, vol. 43, no. 8, pp. 1419-1429, 2012.

[5] T. Sathishkumar, P. Navaneethakrishnan, S. Shankar, R. Rajasekar, and N. Rajini, "Characterization of natural fiber and composites - a review," Journal of Reinforced Plastics and Composites, vol. 32, no. 19, pp. 1457-1476, 2013.

[6] J. Almeida, S. N. Monterio, and L. A. H. Terrones, "Mechanical properties of coir/polyester composites," Elseveir Polym. Test.vol. 27, pp. 591-595, 2008.

[7] P. A. Sreekumar, K. Joseph, G. Unnikrishnan, and S. Thomas, "A comparative study on mechanical properties of sisal-leaf fibre-reinforced polyester composites prepared by resin transfer and compression moulding techniques," Composites Science and Technology, vol. 67, no. 3-4, pp. 453-461, 2007, Mar. 2007.

[8] V. S. Sreenivasan, D. Ravindran, V. Manikandan, and R. Narayanasamy, "Mechanical properties of randomly oriented short Sansevieria cylindrica fibre/polyester composites," Materials \& Design, vol. 32, no. 4, pp. 2444-2455, 2011, Apr. 2011.

[9] M. A. Sawpan, K. L. Pickering, and A. Fernyhough, "Flexural properties of hemp fibre reinforced polylactide and unsaturated polyester composites," Composites Part A: Applied Science and Manufacturing, vol. 43, no. 3, pp. 519-526, 2012, Mar. 2012.

[10] D. R. Mulinari, C. A. R. P. Baptista, J. V. C. Souza, and H. J. C. Voorwald, "Mechanical properties of coconut fibers reinforced polyester composites," Procedia Engineering, vol. 10, pp. 2074-2079, 2011, Jan. 2011.

[11] H. H. Parikh and P. P. Gohil, "Sliding wear experimental investigation and prediction using response surface method: fillers filled fiber reinforced composites," Materials Today: Proceedings, vol. 18, pp. 5388-5393, 2019.

[12] G. V. Vigneshwaran, I. Jenish, and R. Sivasubramanian, "Design, fabrication and experimental analysis of pandanus fibre reinforced polyester composite," Advanced Materials Research, vol. 984-985, no. 985, pp. 253-256, 2014.

[13] J. R. Prabhu Stalin, I. Jenish, and S. Indran, "Tribological charecterization of carbon epoxy composite materials with particulate silane treated SiC fillers," Advanced Materials Research, vol. 984-985, no. 985, pp. 331-335, 2014.

[14] V. K. Thakur, M. K. Thakur, and R. K. Gupta, "Review: raw natural fiber-based polymer composites," International Journal of Polymer Analysis and Characterization, vol. 19, no. 3, pp. 256-271, 2014.

[15] A. Saravana Kumaar, A. Senthilkumar, T. Sornakumar, S. S. Saravanakumar, and V. P. Arthanariesewaran, "Physicochemical properties of new cellulosic fiber extracted from carica papaya bark," Journal of Natural Fibers, vol. 16, no. 2, pp. 175-184, 2017.

[16] S. S. Saravanakumar, A. Kumaravel, T. Nagarajan, and I. G. Moorthy, "Investigation of p-chemical properties of alkali-TreatedProsopis julifloraFibers," International Journal of Polymer Analysis and Characterization, vol. 19, no. 4, pp. 309-317, 2014.
[17] B. Gurukarthik Babu, D. Prince Winston, P. V. Aravind Bhaskar, R. Baskaran, and P. Narayanasamy, "Exploration of electrical, thermal, and mechanical properties of Phaseolus vulgaris fiber/unsaturated polyester resin composite filled with nano-SiO2," Journal of Natural Fibers, vol. 18, no. 12, pp. 2156-2172, 2021.

[18] G. B. Balachandran, P. W. David, A. B. P. Vijayakumar, A. E. Kabeel, M. M. Athikesavan, and R. Sathyamurthy, "Enhancement of PV/T-Integrated single slope solar desalination still productivity using water film cooling and hybrid composite insulation," Environmental Science and Pollution Research, vol. 27, no. 26, pp. 32179-32190, 2019.

[19] T. Sabu, K. Joseph, S. K. Malhotra, K. Goda, and M. S. Sreekala, Polymer Composites Macro- and Microcomposites, Wiley VCH, Weinheim, Germany, 2014.

[20] C. Vigneswaran, M. Ananthasubramanian, and P. Kandhavadivu, Bioprocessing of Textiles, Woodhead Publishing India PVT LTD, New Delhi, 2014.

[21] R. Ganesamoorthy, R. Meenakshi Reddy, T. Raja et al., "Studies on mechanical properties of kevlar/napier grass fibers reinforced with polymer matrix hybrid composite," Advances in Materials Science and Engineering, vol. 2021, pp. 1-9, 2021. 